\title{
Study on the Decorative Pattern of Furniture in the Halls of Tibetan Buddhist Temples in Northwest Sichuan
}

\author{
Lei Yang \\ Art College, Southwest Minzu University, Chengdu, China \\ Email: 457031621@qq.com
}

How to cite this paper: Yang, L. (2019) Study on the Decorative Pattern of Furniture in the Halls of Tibetan Buddhist Temples in Northwest Sichuan. Open Journal of Social Sciences, 7, 259-265. https://doi.org/10.4236/jss.2019.74020

Received: March 20, 2019

Accepted: April 20, 2019

Published: April 23, 2019

Copyright (อ 2019 by author(s) and Scientific Research Publishing Inc. This work is licensed under the Creative Commons Attribution International License (CC BY 4.0).

http://creativecommons.org/licenses/by/4.0/

\begin{abstract}
Furniture in the halls of Tibetan Buddhist temples is an important part and the product of materialization of Tibetan Buddhist culture in Northwest Sichuan. The decorative pattern of the furniture in the halls is the essence of Buddhist culture in Northwest Sichuan, which has unique regional and national characteristics. By excavating the contemporary value and significance of decorative patterns of furniture in the halls of Tibetan Buddhist temples, we can study the influence of the religious culture on the decorative patterns of furniture, and further explore the culture.
\end{abstract}

\section{Keywords}

Tibetan Buddhism, Furniture in the Halls, Decorative Patterns

\section{Overview of Furniture in the Halls of Tibetan Buddhist Temples in Northwest Sichuan}

Northwest Sichuan is located in the southeastern margin of the Qinghai-Tibet Plateau and part of the Hengduan Mountains, with an elevation of 4000 to 4500 meters. It is divided into two parts: the Northwest Sichuan Plateau and the Northwest Sichuan Mountains. The northwest Sichuan plateau is inclined from west to east, which is divided into hilly plateau and high plain, mainly in the area of Nolgai, Hongyuan and Aba. Northwest Sichuan Mountains are divided into Alpine plateau and Alpine Canyon areas. The main mountain ranges are Minshan, Que'er Mountain and Bayan Hara Mountain. Northwest Sichuan has a long history and culture, and is the main area for the exchange and dissemination of Han and Tibetan culture. The unique regional environment in Northwest Sichuan and Tibetan Buddhism combined to form a relatively unique religious 
culture.

A long time ago, Tibetan Buddhist temple was a place for uniting the religion and politics, and it was the highest administrative center in the region. However, most of the Tibetan furniture used by the surrounding residents is spread from the temples. In the history of Northwest Sichuan, there have been many wars and turmoil, so that the temples have been destroyed and rebuilt several times. After the Great Proletarian Cultural Revolution, the temples were demolished, and cultural relics such as Buddha statues and scriptures were destroyed. It was not until 1979 that religious policies were implemented that the temples gradually began to be rebuilt and opened. Religious culture is an ancient culture with a long history and a legacy of Tibetan tradition and historical culture. Nowadays, Tibetan Buddhist temples have formed an irreplaceable bridge between Tibetans and religions. They are the center of spiritual life and have a sacred status.

Furniture in the halls of temples in Northwest Sichuan is influenced by the unique geographical environment, religious culture and unique aesthetic. These form furniture with regional characteristics. The furniture in the halls of temples is mainly divided into three categories: table, cabinet and chair and bed. Table category is mainly divided into the table for sacrificing and the table for scripture. Cabinet category is mainly divided into Buddhist niches, Sutra cabinets and storage cabinets. Chair and bed category is mainly divided into the seat of living Buddha, the seat for chanting sutra, Tibetan bed and so on.

\section{Characteristics of Decorative Patterns of Furniture in the Halls of Tibetan Buddhist Temples in Northwest Sichuan}

As an important part of the Chinese nation, the Tibetan nationality has a long history and culture, strong identification of national culture, and extensive use of religious decorative patterns. In life, these patterns with special meanings are not only used for hanging or decorating, but also for presenting this unique national and religious culture through daily necessities. Throughout the development of Tibetan furniture, we can find that the decorative patterns of furniture not merely serve as the decorative material of furniture, but also contain Tibetan cultural thoughts and wonderful spiritual sustenance.

To study the decorative patterns of furniture in the halls of Tibetan Buddhist temples in Northwest Sichuan is to study the decorative arts of various kinds of furniture. This paper mainly analyses the artistic characteristics and cultural connotations through the subject types, patterns, color implications and decorative materials of the patterns [1].

\subsection{Subject Types}

The decorative subjects of furniture in the halls of Tibetan Buddhist temples are very rich and varied. It can be divided into religion-related symbols and characters. Symbolic subjects include animals, plants, utensils, abstract category, etc. Animals mainly include lion, elephant, tiger and deer. Lotus, hawthorn, Baox- 
iang flower and datura are the most common plant patterns, Utensils are vajra (as shown in Figure 1) golden wheel and so on. Abstract category has Swastika, cloud pattern and so on. Each of these symbols contains profound religious culture. For example, vajra is a typical symbol of the indestructibility of Vajrayana, which symbolizes the elusive, indestructible, unshakable, immutable, invisible and stable state of absolute reality, and that means the consummation of Buddha-nature. Swastika is one of the oldest and most common symbols. It is often painted on Buddha's chest. And in the Vajrayana, it basically means land, one of the four elements, and its unshakable stability.

Character subjects include national figures, portraits, and characters of religious stories, such as Buddha, Bodhisattva, Drolma, Dharmapala and so on. Mostly, the subject of furniture in the halls of the Tibetan Buddhist Temples is the characters of religious stories. Usually these characters are used to set off the Buddhist atmosphere in order to meet the requirements of religious atmosphere (as shown in Figure 2). The decorative theme of Tibetan Buddhist Temple furniture has undergone continuous evolution and development. Its types have been very diverse [2].

\subsection{Pattern Form}

The decorative patterns of furniture in Buddhist temples are various, most of which are concise and practical. The pattern is basically rectangular or square,

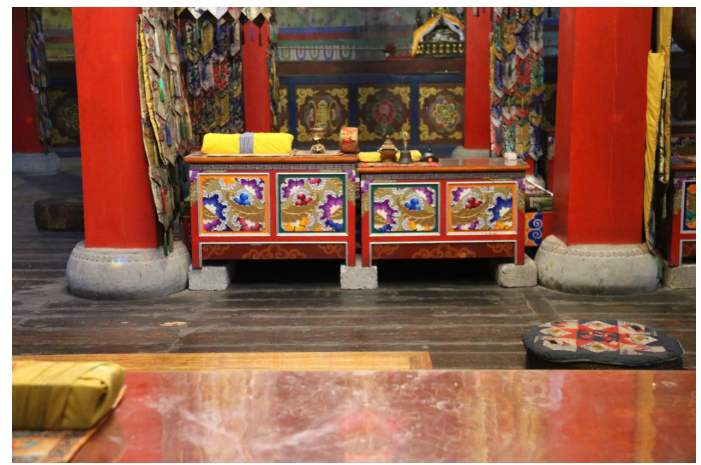

Figure 1. Plant decorative patterns of cabinet (author self-photo).

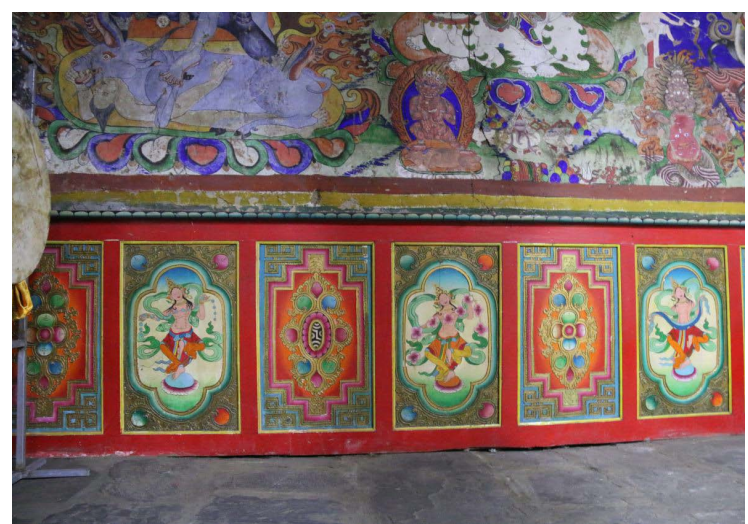

Figure 2. Religious subjects in the halls of Tibetan Buddhist temples (author self-photo). 
showing a relatively stable feature. This form of composition is essentially consistent with the religious spirit of Tibetan Buddhism. Viewed from the exterior and interior structure of furniture, the composition of such a rectangle or square is still primitive and magnificent while the furniture is decorated with rich patterns. It causes mystery to human's vision and psychology.

In Tibetan Buddhist cosmology, the world is divided into three realms: the place where God lives, the forests and lakes in the universe and the place where the Tibetan lives (as shown in Figure 3). This deep-rooted religious thought is particularly prominent on the Tibetan cabinet. The cabinet generally used vertical three-stage design. The surface of the cabinet is divided into multiple rectangles by a robust base, and each enclosed area is a separate decorative area, but it corresponds to the overall decorative pattern and forms unification. Patterns are often reused in the overall composition, so that the segmented areas are still connected and integrated in terms of the overall composition. The decorative details of furniture in Tibetan Buddhist temples mostly reflect the sense of hierarchy and order. And there are certain rules to follow in the formation of patterns. In the furniture composition, decorative patterns and the base circumference has a central point. Even if the decorative pattern has a weak sense of hierarchy, its composition center points are mostly consistent with the base circumference. For example, drawing abstract flower or geometric patterns at the four corners or the center of the four sides of the base in a plane composition. The floor defined by the base circumference is also often divided into two visual levels. Levels are determined by variations in contours that are nearly square or rectangular. The decorative patterns inside and outside the contour line are different.

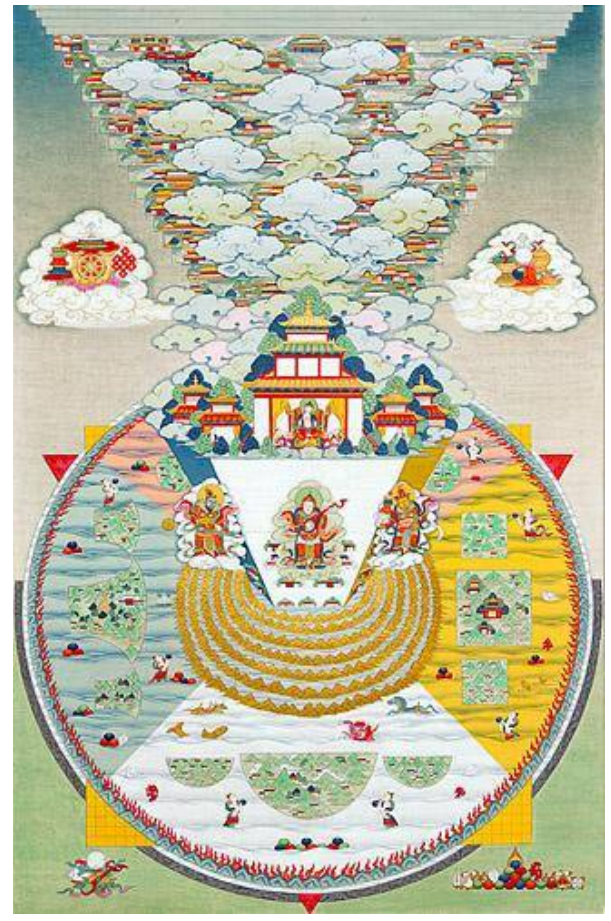

Figure 3. The world view in Tibetan buddhist (from the network). 
Outside the line is an abstract pattern, while inside the line is a large number of painted color patterns, and this layer is the main object of description. Some of the outlines are straight lines and arcs, some are only straight lines, but they all maintain the geometric style.

\subsection{The Implication of Color}

The color of furniture in the halls of Tibetan Buddhism temples is not only the representative of Tibetan furniture style, but also contains strong religious implications. Bkav brgyud, Nyingma and Gelu sects of Tibetan Buddhism are commonly known as white religion, red religion and yellow religion because of the color of their clothes. The ruling groups of politics and religion in different periods have different admiration for different colors, which directly affects the color culture of Tibetan decorative art. Tibetan religious culture has a profound influence on its politics, economy and culture. In the universe of Tibetan Buddhism, Mount Xumi is regarded as the pillar and core of the world. And the east of the mountain is regarded as white silver, the west as red jade, the north as gold, the south as sapphire. Thus, Tibetans have a special mentality of advocating red, white and gold. They regard these as the monarchy in colors. For example, the furniture in the hall of temple is mainly red, and other colors are used as matching colors to blend and embellish. Different colors have different meanings in everyone's mind. However, in Tibetan Buddhism, each color has its specific meaning and is sacred and not offensive. Because of the regional differences, religious cultures and aesthetic concepts, the decorative color of furniture in the halls of Tibetan Buddhist temples has its own unique style. The decorative color of furniture is gorgeous and rich, and pure color is preferred in the use of color because the Tibetan people think that is the color of nature, and without modification and processing is the most beautiful and pure [3].

Red is one of the most representative colors in Tibetan style. The outer walls of the temples of Dharmapala are painted red, and the lama with high social status wears red robes. Now red stands for the noble color, which changes over time. However, using red as the main decorative color is more common, such as in Tibetan palaces, temple buildings and so on. That reflects the Tibetan love of red. In the halls of Tibetan Buddhist temples, red is the main color of furniture decoration, which is most used and most striking. Yellow is also one of the representative colors of Tibetan style. In the Tibetan opera, yellow is the most special color. It symbolizes the broad and sacred, represents the living Buddha, and has the typical symbolic meaning. Yellow is not the main color in Tibetan furniture, but the role of auxiliary color. Tibetan love white for a long time. The Tibetan people's love of white is closely related to the environment in which they live. White snow, white sheep, white clouds are what they see and where they live on every day. So it is the environment that inspires their love for white, and they think that white is the most beautiful and noble. White is often used in the decoration of Tibetan furniture. For example, the cloud pattern is often depicted 
in lace patterns with white lines. Green and blue are the colors that means Tibe$\tan$ life, and they are mostly in the form of auxiliary colors in Tibetan furniture.

\subsection{The Material of Decoration}

Furniture of Tibetan Buddhist temples is rich in materials. Furniture in the halls of Tibetan Buddhist temples in Western Sichuan is mainly made of wood, and supplemented by other decorative materials. Tibet has a vast territory, a relatively large forest coverage, and a relatively large stock of timber. Northwest $\mathrm{Si}$ chuan is located in an alpine region, where the wood texture is very good because of the cold climate. The furniture materials of Tibetan Buddhist temples in the Northwest Sichuan are mainly pine and spruce. Decoration materials are mainly metal, fur, pigments and other materials attached to wood, playing to the characteristics of different materials. Artists and craftsmen use different artistic techniques to process different decorative materials according to their characteristics, so as to exert the artistic characteristics of decorative materials perfectly.

Metals are characterized by easy extension. The main metals used in the furniture of the hall are gold, silver, copper, iron, etc. Among them, copper and iron are the most widely used because the price is lower, the extension is better, and the complex and diverse decorative pattern is easy to be carved.

The main decorative pigments are mineral pigments, plant pigments and animal pigments. Mineral pigments are mainly obtained from some local mines, then polished to decorative pigment. The pigment can avoid artificial processing as far as possible for retaining their naturalness. Plant pigments are mainly milled into color liquid through plants, then boiled and filtered many times, and finally kept dry and shady over time, and stirred with oil evenly.

\section{Conclusion}

The traditional culture embodied in the furniture of Tibetan Buddhist temples in Northwest Sichuan is the spirit and core of Tibetan furniture. The furniture in the hall not merely has the practical function, but also is the carrier of inheriting the spirit of Tibetan Buddhism culture. The strong religious culture and artistic characteristics are injected into furniture's shape and decorative patterns. Its decoration uses the aesthetic ideas and principles of contrast, unity, balance and harmony, and the technology has reached a very high level. Both the main body and the part are permeated with the atmosphere of religious culture everywhere. The study of decorative pattern art of furniture in the halls of Tibetan Buddhist temples in Northwest Sichuan provides rich creative elements for the choice of modelling and decorative art of modern furniture, and is an important carrier for the study of aesthetic thought of Tibetan Buddhism and Tibetan culture. Studying the decorative pattern culture of Tibetan furniture can deepen our understanding of national traditional culture. Understanding the cultural connotation of Tibetan furniture comprehensively and finding out the potential valuable design elements provide an important theoretical basis for the design of modern 
Tibetan furniture. It is greatly significant to the development and inheritance of Tibetan furniture.

\section{Acknowledgements}

This project is funded by the graduate innovation research project of Southwest Minzu University, Project Name: Study on the Decorative Pattern of Furniture in the Halls of Tibetan Buddhist Temples in Northwest Sichuan, project Number: CX2019SZ181.

\section{Conflicts of Interest}

The author declares no conflicts of interest regarding the publication of this paper.

\section{References}

[1] Awangsan (1999) Tibetan Decorative Pattern Art. Tibetan People's Publishing House, Lhasa.

[2] Lu, J. (2010) Appreciation and Collection of Tibetan Furniture. Hunan Fine Arts Publishing House, Changsha.

[3] Duan, H.Y. (2011) Discussion on Decorative Patterns and Styles of Tibetan Furniture. Collector, No. 4, 158-161. 